\title{
Valor nutritivo da forragem e produção animal em pastagens de Brachiaria brizantha
}

\author{
Valéria Pacheco Batista Euclides(1), Manuel Cláudio Motta Macedo(1), Cacilda Borges do Valle(1), \\ Gelson dos Santos Difante ${ }^{(1)}$, Rodrigo Amorim Barbosa ${ }^{(1)}$ e Everton Ronaldo Cacere ${ }^{(1)}$
}

\begin{abstract}
(1)Embrapa Gado de Corte, Caixa Postal 154, CEP 79002-970 Campo Grande, MS. E-mail: val@cnpgc.embrapa.br, macedo@cnpgc.embrapa.br, cacilda@cnpgc.embrapa.br, gdifante@cnpgc.embrapa.br, rodrigo@cnpgc.embrapa.br, evertoncacere@hotmail.com
\end{abstract}

\begin{abstract}
Resumo - O objetivo deste trabalho foi avaliar a produção animal e sua relação com as características dos pastos de Brachiaria brizantha cultivares Marandu, Xaraés e Piatã. O delineamento experimental foi o de blocos ao acaso, com três tratamentos e duas repetições. Os piquetes com 2 ha foram subdivididos em dois e submetidos ao pastejo alternado, com 28 dias de utilização e 28 dias de descanso. Foram utilizados três novilhos teste, por piquete, e novilhos reguladores para manter resíduos pós-pastejo em torno de $3 \mathrm{Mg} \mathrm{ha}^{-1}$ de matéria seca. Mensalmente, os pastos foram avaliados para se estimar o valor nutritivo da forragem. Os animais foram pesados, e as taxas de lotação foram ajustadas duas vezes por semana. No pasto da cv. Xaraés, apesar do menor ganho médio diário (GMD) dos animais, a taxa de lotação foi maior, o que resultou em maior produtividade da cv. Xaraés, em comparação às cvs. Marandu e Piatã. No pasto da cv. Piatã, houve aumento do GMD, o que indica que as cvs. Xaraés e Piatã são novas alternativas para a diversificação dos pastos no Cerrado. Assim, a escolha da forragem deve se dar em razão da meta do sistema de produção, ou seja, a produção por animal ou por área.
\end{abstract}

Termos para indexação: Cerrado, Marandu, Piatã, Xaraés, oferta de forragem, taxa de lotação.

\section{Forage nutritive value and animal production in Brachiaria brizantha pastures}

\begin{abstract}
The objectives of this work were to evaluate animal production and its relationship with pasture characteristics of Brachiaria brizantha cultivars Marandu, Xaraés and Piatã. The experiment had a randomized complete block design, with three treatments and two replicates. Two-ha paddocks were divided into two and submitted to alternated grazing, with 28 days of grazing and 28 days of rest. Three tester steers were kept in each paddock; additional steers were placed in each paddock by the put-and-take technique, to assure post-grazing residues of about $3 \mathrm{Mg} \mathrm{ha}^{-1}$ of dry matter. The pastures were sampled monthly to estimate the nutritive value of the forage. The animals were weighted, and the stocking rate was adjusted twice a week. Despite the lower average daily gain (ADG), in the cv. Xaraés pasture, the stocking rate was greater, which resulted in greater productivity, in comparison with cvs. Marandu and Piatã. The pasture with cv. Piatã had the highest ADG. These results indicate that cvs. Xaraés and Piatã are new alternatives for Cerrado pastures. The choice of the forage cultivar should fit the animal and production system targets.
\end{abstract}

Index terms: Cerrado, Marandu, Piatã, Xaraés, forage allowance, stocking rate.

\section{Introdução}

Brachiaria brizantha cultivar Marandu é uma das espécies forrageiras mais usadas nas áreas de pastagens cultivadas para pecuária no Brasil Central. Estima-se, atualmente, que 50\% das áreas de pastagens cultivadas estejam ocupadas com essa gramínea, na região Centro-Oeste (Macedo, 2006). Na região Norte, as estimativas são de aproximadamente $65 \%$ (Dias Filho \& Andrade, 2005). A grande área ocupada por essa única cultivar e que representa, particularmente, grande diversidade climática, vem, após algum tempo de uso com pastejo, estabelecendo patamar mais elevado de pressão de seleção para pragas e doenças e suas possíveis relações com o clima e o solo (Macedo, 2006). Segundo Valentim et al. (2000), foram constatados casos de morte dessa planta forrageira em extensas áreas no Acre, Pará, Rondônia e em outras localidades da região Amazônica. Focos frequentes 
de morte vêm sendo observados também em Mato Grosso, Maranhão e Tocantins (Valle et al., 2000). Assim, a busca de gramíneas alternativas do gênero Brachiaria, para a composição de um quadro mais diversificado no contexto da exploração pecuária, deve ser uma constante.

Na busca dessas alternativas, 19 acessos selecionados de Brachiaria brizantha foram avaliados em uma rede de ensaios regionais, e os oito melhores, conforme análise conjunta entre locais (Valle et al., 2004), foram avaliados sob pastejo, em pequenas parcelas, dos quais quatro se mostraram promissores e bem adaptados à região do Cerrado (Euclides et al., 2001). Desses, dois foram selecionados para a avaliação da produção animal.

No entanto, seria expectativa muito otimista supor que as medidas de crescimento e de qualidade das forrageiras, sob regime de corte, representassem estimativas confiáveis da produção animal sob pastejo. Portanto, como não se tem habilidade suficiente para simular a seletividade animal por meio de cortes (Moraes et al., 2005), bem como não se consegue estimar o efeito da desfolha imposta pelo animal sobre o pasto (Trindade et al., 2007), há necessidade de usar o próprio animal na avaliação de forrageiras (Euclides \& Euclides Filho, 1998).

A proposta de lançamento de cultivares forrageiras, adotada pela Embrapa (Euclides \& Euclides Filho, 1998), requer a avaliação integrada dos acessos pré-selecionados e do uso de animais como partes integrantes da proposta experimental, antes da incorporação do novo material ao sistema de produção. Ademais, com a regulamentação da legislação sobre lançamento de cultivares forrageiras, faz-se necessário o desenvolvimento de estudos sobre o valor de cultivo e uso (VCU), que tem a função de assegurar aos usuários a informação adequada e segura sobre o novo material genético a ser colocado à disposição do mercado (Brasil, 2008).

O objetivo deste trabalho foi avaliar as produções por animal e por área e suas relações com as características dos pastos de Brachiaria brizantha cultivares Marandu, Xaraés e Piatã .

\section{Material e Métodos}

O experimento foi conduzido na Embrapa Gado de Corte $\left(20^{\circ} 27^{\prime} \mathrm{S}, 54^{\circ} 37^{\prime} \mathrm{W}\right.$ e altitude de $\left.530 \mathrm{~m}\right)$, Campo
Grande, MS, de maio de 2001 a abril de 2004. O padrão climático da região, segundo Köppen, é o da faixa de transição entre $\mathrm{Cfa}$ e $\mathrm{Aw}$ tropical úmido. A precipitação média anual é de $1.560 \mathrm{~mm}$, e o período considerado de seca vai de maio a setembro ( $30 \%$ da precipitação anual). As temperaturas, as precipitações e o balanço hídrico do período experimental encontram-se em Euclides et al. (2008b). O solo da área experimental é classificado como Latossolo Vermelho distrófico (Embrapa, 1999).

$\mathrm{Na}$ implantação, a área experimental foi corrigida e

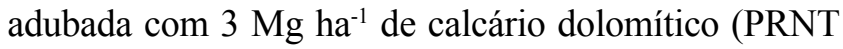
$75 \%$ ) e $80 \mathrm{~kg} \mathrm{ha}^{-1}$ de $\mathrm{P}_{2} \mathrm{O}_{5}$ e de $\mathrm{K}_{2} \mathrm{O}$, e $32 \mathrm{~kg} \mathrm{ha}^{-1}$ de micronutrientes FTE BR-12. De outubro a novembro de cada ano, foram aplicados, em cobertura, $40 \mathrm{~kg} \mathrm{ha}^{-1}$ de $\mathrm{P}_{2} \mathrm{O}_{5}$ e de $\mathrm{K}_{2} \mathrm{O}$ e, de novembro a dezembro, foram aplicados $50 \mathrm{~kg} \mathrm{ha}^{-1}$ de $\mathrm{N}$, na forma de uréia. Em dezembro de 2003, foram aplicados, em cobertura, $2 \mathrm{Mg} \mathrm{ha}^{-1}$ de calcário dolomítico (PRNT 75\%), com o objetivo de manter os patamares de saturação por bases do solo acima de $40 \%$. Detalhes sobre o preparo do solo, plantio, correções e adubações encontram-se em Euclides et al. (2008b).

O delineamento experimental foi o de blocos ao acaso, com três tratamentos e duas repetições. Os tratamentos foram dois ecótipos de B. brizantha, B178 (cultivar Xaraés) e B112 (cultivar Piatã) e, como testemunha, foi utilizada a $B$. brizantha cultivar Marandu.

Os piquetes de 2 ha foram subdivididos em dois e submetidos ao pastejo alternado, com 28 dias de utilização e 28 dias de descanso. Cada piquete foi pastejado por três novilhos (animais teste), distribuídos ao acaso. As taxas de lotação foram ajustadas duas vezes por semana, por meio de animais reguladores, da mesma categoria, que eram colocados e removidos de cada piquete, de acordo com a disponibilidade de forragem. Isto assegurou, entre os tratamentos, resíduos pós-pastejo em torno de $3 \mathrm{Mg} \mathrm{ha}^{-1}$ de matéria seca. Anualmente, em maio, os animais foram substituídos por outros animais da mesma categoria.

A cada 28 dias, todos os animais eram pesados após jejum de, aproximadamente, 15 horas. $\mathrm{O}$ ganho diário de peso dos animais-teste foi usado para estimar a qualidade do pasto. Também foi computado o número de dias em que os animais reguladores permaneceram na pastagem. Assim, os animais-teste e os animais reguladores, combinados, possibilitaram as estimativas da capacidade de suporte dos pastos e da produção de peso corporal por área. 
Tanto no pré como no pós-pastejo, foram feitas amostragens de massa de forragem. Para se estimar a massa de forragem, foram cortadas ao nível do solo, 40 amostras de $1 \mathrm{~m}^{2}$, em cada piquete, as quais foram divididas em duas subamostras: uma foi seca e pesada, e a outra foi separada em lâmina foliar, colmo (bainha e colmo) e material morto. A proporção de cada componente morfológico foi expressa como percentagem do peso total. Para as amostras relativas ao pré-pastejo, de cada dez amostras de lâmina foliar e colmos, foram feitas amostras compostas, que foram moídas e analisadas para se estimar o valor nutritivo. Adicionalmente, no pré-pastejo, foram coletadas duas amostras que simularam o pastejo animal em cada piquete, para se estimar o valor nutritivo.

Para a avaliação dos teores de proteína bruta (PB), fibra em detergente neutro (FDN), lignina em detergente ácido(LDA) e digestibilidade in vitro da matéria orgânica (DIVMO), utilizou-se a espectroscopia de reflectância do infravermelho próximo (NIRS), conforme Marten et al. (1985). Os dados de reflectância das amostras, na faixa de comprimentos de onda de 1.100 a $2.500 \eta \mathrm{m}$, foram armazenados por um espectrômetro modelo NR5000 acoplado a um microcomputador.

A cada 28 dias, a oferta de lâmina foliar (quilograma de matéria seca de lâmina foliar por $100 \mathrm{~kg}$ de peso corporal por dia) foi calculada pela soma da massa de matéria seca de lâmina foliar (LF), presente no pré-pastejo, e o acúmulo de LF correspondente ao período de pastejo, obtido a partir da diferença entre a massa de lâmina foliar no pré-pastejo atual e a massa de lâmina foliar no pós-pastejo do ciclo de pastejo anterior, dividida pelo total de peso corporal (PC) mantido no piquete no mesmo período.

Os dados foram agrupados por época do ano - de maio a setembro (período seco) e de outubro a abril (período das águas) - e analisados por um modelo matemático com os efeitos fixos de tratamento, bloco, período do ano e ano de avaliação, e as interações entre esses.
Todas as análises foram feitas pelo método dos quadrados mínimos, pelo procedimento "general linear model", disponível no SAS (SAS Institute, 1996). Os comandos "random" e "test" foram usados para a identificação e realização dos testes apropriados para cada variável independente. A comparação de médias foi realizada pelo teste de Tukey, a 5\% de probabilidade. No caso de interações significativas, a comparação de média foi realizada por meio da probabilidade da diferença e pelo teste t de Student, a $5 \%$ de probabilidade.

\section{Resultados e Discussão}

O teor de proteína bruta $(\mathrm{PB})$ no componente lâmina foliar (LF), no pré-pastejo, foi semelhante para as três cultivares $(p>0,05)$. No entanto, a cv. Marandu apresentou teores menores $(p<0,01)$ de fibra em detergente neutro $(\mathrm{FDN})$ e lignina em detergente ácido (LDA) e, consequentemente, maior $(\mathrm{p}<0,01)$ digestibilidade in vitro da matéria orgânica (DIVMO), quando comparada às cvs. Xaraés e Piatã (Tabela 1). A tendência dos resultados da LF se repetiu nos dos colmos das três cultivares que apresentaram, em pré-pastejo, teores de PB semelhantes $(\mathrm{p}>0,05)$ entre si; no entanto, o colmo da cv. Marandu apresentou maior $(p<0,05)$ DIVMO e menores $(p<0,05)$ teores de FDN e de LDA, em comparação aos colmos das cvs. Piatã e Xaraés (Tabela 1). Nave (2007) observou nas lâminas foliares e nos colmos da cv. Xaraés, manejada com 28 dias de descanso, teores de PB (12,2 e 7,1\%) e de DIVMO (65,6 e 67,9\%) superiores e de FDN $(68,7$ e $76,4 \%)$ inferiores aos dos encontrados para essa cultivar no presente trabalho (Tabela 1). Provavelmente, o melhor valor nutritivo, encontrado por esse autor, se deveu ao curto período de avaliação, outubro a março (período das águas). Os resultados apresentados na Tabela 1 correspondem às médias dos períodos das águas e seco, durante três anos de avaliação.

Tabela 1. Médias dos quadrados mínimos e erros-padrão da média(EPM), para os teores de proteína bruta (PB), de digestibilidade in vitro da matéria orgânica (DIVMO), de fibra em detergente neutro (FDN) e de lignina em detergente ácido (LDA), nas lâminas foliares (LF) e colmos (Co) dos pastos de B. brizantha, cultivares Marandu, Piatã e Xaraés, na condição de pré-pastejo ${ }^{(1)}$.

\begin{tabular}{|c|c|c|c|c|c|c|c|c|}
\hline \multirow[t]{2}{*}{ Cultivar } & \multicolumn{2}{|c|}{ PB (\%) } & \multicolumn{2}{|c|}{ DIVMO (\%) } & \multicolumn{2}{|c|}{ FDN (\%) } & \multicolumn{2}{|c|}{ LDA (\%) } \\
\hline & LF & $\mathrm{Co}$ & $\mathrm{LF}$ & $\mathrm{Co}$ & LF & $\mathrm{Co}$ & LF & $\mathrm{Co}$ \\
\hline Marandu & $8,2 \mathrm{a}$ & $4,7 \mathrm{a}$ & $53,2 a$ & $43,1 \mathrm{a}$ & $70,1 \mathrm{~b}$ & $78,7 b$ & $3,2 b$ & $4,6 c$ \\
\hline Piatã & $8,2 \mathrm{a}$ & $4,6 \mathrm{a}$ & $50,1 b$ & $40,0 \mathrm{~b}$ & $73,0 \mathrm{a}$ & $80,7 a$ & $3,3 b$ & $4,8 \mathrm{~b}$ \\
\hline Xaraés & $8,2 \mathrm{a}$ & $4,4 \mathrm{a}$ & $48,7 b$ & $40,9 \mathrm{ab}$ & $72,9 a$ & $79,9 a$ & $3,6 \mathrm{a}$ & $5,0 \mathrm{a}$ \\
\hline EPM & 0,13 & 0,09 & 0,24 & 0,29 & 0,32 & 0,26 & 0,02 & 0,004 \\
\hline
\end{tabular}

${ }^{(1)}$ Médias seguidas de letras iguais, nas colunas, não diferem entre si pelo teste de Tukey, a 5\% de probabilidade. 
Para as variáveis associadas ao valor nutritivo, exceto para o teor de LDA na LF, no pré-pastejo, foram observados efeitos do ano experimental $(p<0,01)$ e da interação $(\mathrm{p}<0,05)$ entre período do ano e de ano experimental (Tabela 2). Independentemente da cultivar, essas variações no valor nutritivo, entre anos e período do ano, foram consequências das variações climáticas ocorridas durante os anos experimentais (Euclides et al., 2008b), além das diferentes épocas de florescimento dessas cultivares (Valle et al., 2004), já que esses fatores são determinantes na expressão do valor nutritivo potencial da forrageira.

É comum, em experimentos com animais em pastejo, cortar a planta rente ao solo, separá-la em seus componentes e usar a LF para se estimar o valor nutritivo da dieta do animal. No entanto, Euclides et al. (1992) observaram que, pela simulação do pastejo animal, pode-se ter uma estimativa satisfatória do valor nutritivo da dieta dos animais em pastejo; e que o valor nutritivo da LF de uma amostra tradicional não é representativo da dieta selecionada pelo animal. Assim, as variáveis associadas ao valor nutritivo foram, também, analisadas nas amostras do pastejo, que foram consideradas como as representativas da dieta dos animais. Observou-se maior $(p<0,05)$ valor nutritivo das amostras do pastejo simulado, quando comparadas ao do componente LF (Tabela 3), o que pode ser atribuído à maior presença de folhas novas nas amostras coletadas apenas no horizonte potencialmente pastejado pelo animal, ou seja, acima da altura do provável resíduo. As amostras retiradas rente ao solo contêm, além das folhas novas, as que iniciaram o processo de senescência, quer seja pelo sombreamento ou por terem sido refugadas pelo animal.

Considerando-se as amostras do pastejo simulado, no pré-pastejo, os teores de PB, DIVMO e LDA foram semelhantes $(p>0,05)$ nos pastos das diferentes cultivares. No entanto, a cv. Piatã apresentou maior $(p<0,05)$ teor de FDN do que a cv. Marandu, enquanto a cv. Xaraés apresentou teor semelhante ao das outras duas (Tabela 4). Houve efeitos de período do ano $(\mathrm{p}<0,01)$, em todas as variáveis associadas ao valor nutritivo. As médias da DIVMO foram 58,3 $\pm 0,6 \mathrm{e}$ $52,4 \pm 0,6 \%$, e da LDA foram $2,9 \pm 0,04$ e $3,2 \pm 0,04 \%$, no período das águas e da seca, respectivamente. Também, foram observadas diferenças $(p<0,01)$ entre anos, em todas as variáveis. Foi significativa, também, a interação $(p<0,05)$ entre os efeitos de período do ano e de ano experimental, quanto aos teores de PB e FDN (Tabela 5). Independentemente do ano experimental, os teores de $\mathrm{PB}$ foram maiores durante o período das águas, quando comparados aos do período seco. Os conteúdos de FDN foram semelhantes entre os períodos do ano, exceto para o segundo ano, quando o

Tabela 2. Médias dos quadrados mínimos, para os teores de proteína bruta (PB), de digestibilidade in vitro da matéria orgânica (DIVMO), de fibra em detergente neutro (FDN) e de lignina em detergente ácido (LDA), nas lâminas foliares e colmos dos pastos de B. brizantha, cultivares Marandu, Piatã e Xaraés, na condição de pré-pastejo, de acordo com o ano experimental e o período do ano ${ }^{(1)}$.

\begin{tabular}{|c|c|c|c|c|c|c|c|c|}
\hline \multirow{2}{*}{$\begin{array}{l}\text { Ano } \\
\text { experimental }\end{array}$} & \multicolumn{2}{|c|}{ PB (\%) } & \multicolumn{2}{|c|}{ DIVMO (\%) } & \multicolumn{2}{|c|}{ FDN (\%) } & \multicolumn{2}{|c|}{ LDA (\%) } \\
\hline & Seca & Águas & Seca & Águas & Seca & Águas & Seca & Águas \\
\hline & \multicolumn{8}{|c|}{ Lâmina foliar } \\
\hline \multirow[t]{2}{*}{$2001 / 2002$} & 8,9Aa & $9,2 \mathrm{Aa}$ & $52,1 \mathrm{Aa}$ & $50,1 \mathrm{Aa}$ & $70,2 \mathrm{Ab}$ & $72,8 \mathrm{Aa}$ & 3,3 & 3,4 \\
\hline & $(0,19)$ & $(0,17)$ & $(0,77)$ & $(0,65)$ & $(0,48)$ & $(0,41)$ & $(0,06)$ & $(0,05)$ \\
\hline \multirow[t]{2}{*}{$2002 / 2003$} & $7,1 \mathrm{Bb}$ & $7,8 \mathrm{Aa}$ & $47,5 \mathrm{Bb}$ & $51,6 \mathrm{Aa}$ & $71,8 \mathrm{Aa}$ & $72,0 \mathrm{Aa}$ & 3,2 & 3,3 \\
\hline & $(0,19)$ & $(0,17)$ & $(0,77)$ & $(0,65)$ & $(0,48)$ & $(0,41)$ & $(0,06)$ & $(0,05)$ \\
\hline \multirow{2}{*}{$2003 / 2004$} & $7,8 \mathrm{Ba}$ & 7,3Aa & $52,6 \mathrm{Aa}$ & 49,8Аaа & $72,1 \mathrm{Aa}$ & $73,1 \mathrm{Aa}$ & 3,5 & 3,6 \\
\hline & $(0,19)$ & $(0,17)$ & $(0,77)$ & $(0,65)$ & $(0,48)$ & $(0,41)$ & $(0,06)$ & $(0,05)$ \\
\hline \multirow[t]{3}{*}{ Média } & 7,9 & 8,1 & 50,8 & 50,5 & 71,4 & 72,6 & 3,3 & 3,4 \\
\hline & $(0,11)$ & $(0,10)$ & $(0,44)$ & $(0,37)$ & $(0,28)$ & $(0,23)$ & $(0,04)$ & $(0,03)$ \\
\hline & \multicolumn{8}{|c|}{ Colmo } \\
\hline \multirow[t]{2}{*}{$2001 / 2002$} & $4,9 \mathrm{Aa}$ & $5,4 \mathrm{Aa}$ & $41,0 \mathrm{Aa}$ & $41,2 \mathrm{Aa}$ & $79,0 \mathrm{Ba}$ & $80,3 \mathrm{Aa}$ & $4,7 \mathrm{Ba}$ & $4,5 \mathrm{Aa}$ \\
\hline & $(0,14)$ & $(0,12)$ & $(0,80)$ & $(0,68)$ & $(0,39)$ & $(0,33)$ & $(0,09)$ & $(0,07)$ \\
\hline \multirow[t]{2}{*}{$2002 / 2003$} & $4,3 \mathrm{Ba}$ & $4,6 \mathrm{Ba}$ & $41,8 \mathrm{Aa}$ & $43,4 \mathrm{ABa}$ & $77,9 \mathrm{Bb}$ & $79,7 \mathrm{Aa}$ & $4,2 \mathrm{Cb}$ & $4,6 \mathrm{Aa}$ \\
\hline & $(0,14)$ & $(0,12)$ & $(0,80)$ & $(0,68)$ & $(0,39)$ & $(0,33)$ & $(0,09)$ & $(0,07)$ \\
\hline \multirow[t]{2}{*}{$2003 / 2004$} & $3,2 \mathrm{Cb}$ & $5,0 \mathrm{ABa}$ & $36,3 \mathrm{Ab}$ & $44,3 \mathrm{Ba}$ & $82,2 \mathrm{Aa}$ & $79,4 \mathrm{Ab}$ & $6,0 \mathrm{Aa}$ & $4,8 \mathrm{Ab}$ \\
\hline & $(0,14)$ & $(0,12)$ & $(0,80)$ & $(0,68)$ & $(0,39)$ & $(0,33)$ & $(0,09)$ & $(0,07)$ \\
\hline \multirow[t]{2}{*}{ Média } & 4,1 & 5,0 & 39,7 & 43,0 & 79,7 & 79,8 & 4,9 & 4,6 \\
\hline & $(0,08)$ & $(0,07)$ & $(0,46)$ & $(0,39)$ & $(0,23)$ & $(0,19)$ & $(0,04)$ & $(0,05)$ \\
\hline
\end{tabular}

${ }^{(1)}$ Médias seguidas de letras iguais, maiúsculas nas colunas e minúsculas nas linhas, dentro de período do ano, não diferem entre si pelo teste de Tukey, a 5\% de probabilidade; os valores entre parênteses são os erros-padrão da média. 
teor foi menor no período das águas. De maneira geral, o valor nutritivo da forrageira decresceu do primeiro para o terceiro ano experimental.

Os valores nutritivos dos resíduos pós-pastejo foram semelhantes $(p>0,05)$ entre os períodos do ano e entre os anos experimentais, e não foram observadas interações entre esses efeitos. O resíduo do pasto da cv. Marandu apresentou os menores teores de FDN e de LDA e, consequentemente, maior DIVMO, quando comparada aos pastos das cvs. Piatã e Xaraés (Tabela 4). A progressiva desfolha do dossel, com o decorrer do período de pastejo, teve reflexo negativo nos valores nutritivos dos resíduos (Euclides et al., 2008b). Assim, independentemente das cultivares, houve decréscimo $(\mathrm{p}<0,01)$ nos teores de PB e DIVMO e acréscimos $(\mathrm{p}<0,01)$ nos conteúdos de FDN e LDA (Tabela 4), do pré para o pós-pastejo. $\mathrm{O}$ que confirma o pastejo seletivo dos animais.

Os ganhos de peso dos animais variaram $(\mathrm{p}<0,01)$ conforme a cultivar sob pastejo. Houve diferenças entre período do ano $(p<0,01)$ e entre anos $(p<0,05)$ e interação significativa $(p<0,05)$ entre os efeitos de cultivar, de período do ano e ano experimental (Tabela 6). Durante o período seco, os ganhos médios diários (GMD) dos animais que pastejaram em pastos

Tabela 3. Médias dos quadrados mínimos e os erros-padrão da média (EPM), para os teores de proteína bruta (PB), de digestibilidade in vitro da matéria orgânica (DIVMO), de fibra em detergente neutro (FDN) e de lignina em detergente ácido (LDA), nas lâminas foliares e colmos, e na amostra que simulou o pastejo animal, na condição de pré-pastejo, dos pastos $B$. brizantha cultivares Marandu, Piatã e Xaraés ${ }^{(1)}$.

\begin{tabular}{lcccc}
\hline Característica & PB (\%) & DIVMO (\%) & FDN (\%) & LDA (\%) \\
\hline Lâmina foliar & $8,0 \mathrm{~b}$ & $50,6 \mathrm{~b}$ & $72,0 \mathrm{~b}$ & $3,4 \mathrm{~b}$ \\
Simulando o pastejo & $8,8 \mathrm{a}$ & $55,3 \mathrm{a}$ & $73,7 \mathrm{a}$ & $3,0 \mathrm{a}$ \\
\hline EPM & 0,04 & 0,15 & 0,18 & 0,02 \\
\hline
\end{tabular}

${ }^{(1)}$ Médias seguidas de letras iguais não diferem entre si, a $5 \%$ de probabilidade. com as três cultivares foram semelhantes, exceto durante a primeira seca (2001), quando o GMD foi maior para os animais que pastejaram a cv. Piatã (Tabela 6). No período das águas, durante o primeiro e o terceiro anos experimentais, o GMD dos animais que pastejaram a cv. Xaraés foi inferior aos dos animais que pastejaram as cvs. Marandu e Piatã. Os GMD de animais que pastejaram a cv. Marandu foram semelhantes aos observados por Postiglioni (1998), para essa cultivar, sob lotação contínua. Os GMD dos animais que pastejaram as cvs. Marandu e Xaraés foram semelhantes aos dos animais estudados por Pereira et al. (2005) que pastejaram essas mesmas cultivares, sob o mesmo manejo, no Sul da Bahia.

As variações nos GMD dos animais entre cultivares, épocas do ano e anos experimentais não puderam ser explicadas pelas variações no valor nutritivo dos pastos. Apesar das correlações entre GMD e as variáveis associadas ao valor nutritivo terem sido significativas ( $p<0,01)$, os coeficientes de correlação (r) foram muito baixos, de $0,46,0,47,-0,27$ e $-0,23$, para PB, DIVMO, FDN e LDA, respectivamente. Vários autores (Euclides et al., 2000; Palhano et al., 2007; Trindade et al., 2007) demonstraram que a estrutura do pasto é mais importante do que o valor nutritivo, no controle do consumo de forragem pelos animais que pastejam capim-marandu sob diferentes manejos. Poppi et al. (1987) afirmam que o consumo de forragem por animais em pastejo pode ser controlado por fatores não nutricionais relacionados ao comportamento ingestivo.

Assim, o consumo restrito de nutrientes é o principal fator que limita a produção animal, e só será controlado pelo valor nutritivo da forragem se a quantidade de forragem disponível não for limitante. No entanto, em consequência do manejo adotado, pode-se assumir que a massa de forragem não foi limitante, uma vez que os resíduos de forragem pós-pastejo foram sempre

Tabela 4. Médias dos quadrados mínimos e os erros-padrão da média (EPM), para os teores de proteína bruta (PB), de digestibilidade in vitro da matéria orgânica (DIVMO), de fibra em detergente neutro (FDN) e de lignina em detergente ácido (LDA), nas amostras que simularam o pastejo animal, nas condições de pré e pós-pastejo, dos pastos de $B$. brizantha cultivares Marandu, Piatã e Xaraés ${ }^{(1)}$.

\begin{tabular}{|c|c|c|c|c|c|c|c|c|}
\hline \multirow[t]{2}{*}{ Cultivar } & \multicolumn{2}{|c|}{ PB (\%) } & \multicolumn{2}{|c|}{ DIVMO (\%) } & \multicolumn{2}{|c|}{ FDN (\%) } & \multicolumn{2}{|c|}{ LDA(\%) } \\
\hline & Pré & Pós & Pré & Pós & Pré & Pós & Pré & Pós \\
\hline Marandu & $8,8 \mathrm{Aa}$ & $6,8 \mathrm{Ab}$ & $56,1 \mathrm{Aa}$ & $50,5 \mathrm{Ab}$ & $72,4 \mathrm{Bb}$ & $74,1 \mathrm{Ba}$ & $2,9 \mathrm{Ab}$ & $3,2 \mathrm{Ba}$ \\
\hline Piatã & $8,3 \mathrm{Ab}$ & $6,0 \mathrm{Ab}$ & $55,0 \mathrm{Aa}$ & $47,4 \mathrm{Bb}$ & $75,1 \mathrm{Ab}$ & $77,4 \mathrm{Aa}$ & $3,2 \mathrm{Ab}$ & $3,6 \mathrm{Aa}$ \\
\hline Xaraés & $9,1 \mathrm{Ab}$ & $6,6 \mathrm{Ab}$ & $54,8 \mathrm{Aa}$ & $47,7 \mathrm{Bb}$ & $73,7 \mathrm{ABb}$ & $76,6 \mathrm{Aa}$ & $3,0 \mathrm{Ab}$ & $3,6 \mathrm{Aa}$ \\
\hline EPM & 0,2 & 0,2 & 0,7 & 0,6 & 0,4 & 0,4 & 0,05 & 0,06 \\
\hline
\end{tabular}

${ }^{(1)}$ Médias seguidas de letras iguais, maiúsculas nas colunas e minúsculas nas linhas, não diferem entre si pelo teste de Tukey, a 5\% de probabilidade. 
cerca de $3 \mathrm{Mg} \mathrm{ha}^{-1}$ (Euclides et al., 2008b). Todavia, Euclides et al. (2000) observaram independência entre a massa de forragem total e consumo de forragem pelos animais, em pastos de $B$. brizantha e $B$. decumbens. Porém, esses autores encontraram correlação positiva entre a massa de lâmina foliar (LF) e a ingestão de forragem pelos animais. Optou-se, dessa forma, por expressar a oferta de forragem com base na matéria seca de LF (quilograma de MSLF por $100 \mathrm{~kg}$ de peso corporal (PC) por dia).

A oferta de MSLF em $\mathrm{kg}$ por $100 \mathrm{~kg}$ de PC por dia, durante todo o período experimental, foi maior $(\mathrm{p}<0,01)$ nos pastos da cv. Piatã $(7,8)$, seguida daquelas dos pastos das cvs. Marandu $(6,8)$ e Xaraés $(6,4)$, com erro padrão da média de 0,04 . Houve, ainda, diferenças entre anos $(\mathrm{p}<0,01)$ na oferta de MSLF, que foi 7,0 no primeiro, 6,2 no segundo e 7,8 no terceiro ano experimental, com erro-padrão da média de 0,25 . Não houve efeito do período do ano $(p>0,05)$ e nem das interações simples $(p>0,05)$. Provavelmente, essas menores ofertas de MSLF do pasto da cv. Xaraés, durante o segundo ano experimental, foram responsáveis pelos menores GMD observados durante o período das águas, para a cv. Xaraés, e durante o segundo ano para as cvs. Marandu e Piatã (Tabela 6). No entanto, as MSLF observadas estão dentro da faixa de 4 a $11 \mathrm{~kg}$ por $100 \mathrm{~kg}$ de PC por dia, considerada ótima por Euclides et al. (2008a), com base em vários trabalhos conduzidos com gramíneas tropicais. Isto indica que a oferta de forragem não foi o principal fator limitante do consumo e, consequentemente, do desempenho animal, e pode ser confirmado pela ausência de correlação $(p>0,05)$ entre o GMD e a oferta de MSLF.

Segundo Walker (1995), a seleção da dieta é o fator mais importante do processo que influencia a condição nutricional do animal. Assim, variações no processo de pastejo, em consequência das modificações na estrutura do dossel, podem influenciar de forma relevante $o$ consumo de forragem. As características estruturais do pasto tornam-se, portanto, importantes controladores do consumo de forragem pelos animais. Houve grande variação na estrutura do dossel forrageiro, ao longo do período experimental, expressada na relação lâmina foliar:colmo (RFC) e lâmina foliar:material morto (RFM). As médias para a RFC foram de 1,9, 1,6 e 1,9, durante o período das águas, e de $0,8,1,0$ e 0,6 , no

Tabela 5. Médias dos quadrados mínimos, para os teores de proteína bruta (PB), de digestibilidade in vitro da matéria orgânica (DIVMO), de fibra em detergente neutro (FDN) e de lignina em detergente ácido (LDA), nas amostras que simularam o pastejo animal, na condição de pré-pastejo, de acordo com o ano experimental e o período do ano ${ }^{(1)}$.

\begin{tabular}{|c|c|c|c|c|c|c|}
\hline \multirow{2}{*}{$\begin{array}{l}\text { Ano } \\
\text { experimental }\end{array}$} & \multicolumn{2}{|c|}{ PB (\%) } & \multicolumn{2}{|c|}{ FDN $(\%)$} & \multirow{2}{*}{$\begin{array}{c}\text { DIVMO (\%) } \\
\text { Média }\end{array}$} & \multirow{2}{*}{$\begin{array}{l}\text { LDA (\%) } \\
\text { Média }\end{array}$} \\
\hline & Seca & Águas & Seca & Águas & & \\
\hline $2001 / 2002$ & $\begin{array}{l}8,6 \mathrm{Ab} \\
(0,32)\end{array}$ & $\begin{array}{c}10,4 \mathrm{Aa} \\
(0,32)\end{array}$ & $\begin{array}{c}73,9 \mathrm{Aa} \\
(0,64)\end{array}$ & $\begin{array}{c}72,8 \mathrm{aAa} \\
(0,64)\end{array}$ & $\begin{array}{l}57,7 \mathrm{~A} \\
(0,74)\end{array}$ & $\begin{array}{c}2,8 \mathrm{~B} \\
(0,05)\end{array}$ \\
\hline $2002 / 2003$ & $\begin{array}{l}6,7 \mathrm{Bb} \\
(0,32)\end{array}$ & $\begin{array}{c}10,1 \mathrm{ABa} \\
(0,27)\end{array}$ & $\begin{array}{c}75,3 \mathrm{Aa} \\
(0,64)\end{array}$ & $\begin{array}{c}71,7 \mathrm{Ab} \\
(0,54)\end{array}$ & $\begin{array}{l}54,0 \mathrm{~B} \\
(0,69)\end{array}$ & $\begin{array}{l}2,9 \mathrm{~B} \\
(0,05)\end{array}$ \\
\hline $2003 / 2004$ & $\begin{array}{c}7,4 \mathrm{ABb} \\
(0,32)\end{array}$ & $\begin{array}{l}9,1 \mathrm{Ba} \\
(0,27)\end{array}$ & $\begin{array}{c}75,0 \mathrm{Aa} \\
(0,64)\end{array}$ & $\begin{array}{c}73,7 \mathrm{Aa} \\
(0,54)\end{array}$ & $\begin{array}{l}54,3 \mathrm{~B} \\
(0,69)\end{array}$ & $\begin{array}{c}3,4 \mathrm{~A} \\
(0,04)\end{array}$ \\
\hline Média & $\begin{array}{c}7,6 \\
(0,19)\end{array}$ & $\begin{array}{c}9,9 \\
(0,16)\end{array}$ & $\begin{array}{c}74,7 \\
(0,33)\end{array}$ & $\begin{array}{c}72,7 \\
(0,33)\end{array}$ & - & - \\
\hline
\end{tabular}

${ }^{(1)}$ Médias seguidas de letras iguais, maiúsculas nas colunas e minúsculas nas linhas, não diferem entre si pelo teste de Tukey, a $5 \%$ de probabilidade; os valores entre parênteses são os erros-padrão da média.

Tabela 6. Médias dos quadrados mínimos, para o ganho médio diário (g/novilho) dos novilhos, em pastos de $B$. brizantha cultivares Marandu, Xaraés e Piatã, de acordo com o ano experimental e o período do ano ${ }^{(1)}$.

\begin{tabular}{|c|c|c|c|c|c|c|}
\hline \multirow{2}{*}{$\begin{array}{l}\text { Ano } \\
\text { experimental }\end{array}$} & \multicolumn{3}{|c|}{ Período das águas } & \multicolumn{3}{|c|}{ Período seco } \\
\hline & Marandu & Xaraés & Piatã & Marandu & Xaraés & Piatã \\
\hline $2001 / 2002$ & $\begin{array}{c}845 \mathrm{Aa} \\
(22)\end{array}$ & $\begin{array}{c}730 \mathrm{Ab} \\
(22)\end{array}$ & $\begin{array}{c}815 \mathrm{Aa} \\
(22)\end{array}$ & $\begin{array}{c}275 \mathrm{Ab} \\
(26)\end{array}$ & $\begin{array}{c}240 \mathrm{Ab} \\
(26)\end{array}$ & $\begin{array}{c}445 \mathrm{Aa} \\
(26)\end{array}$ \\
\hline $2002 / 2003$ & $\begin{array}{l}610 \mathrm{Ba} \\
(25)\end{array}$ & $\begin{array}{l}\text { 630Aa } \\
(23)\end{array}$ & $\begin{array}{c}685 \mathrm{Ba} \\
(25)\end{array}$ & $\begin{array}{c}335 \mathrm{Aa} \\
(26)\end{array}$ & $\begin{array}{c}325 \mathrm{Aa} \\
(29)\end{array}$ & $\begin{array}{c}\text { 300Aa } \\
(26)\end{array}$ \\
\hline $2003 / 2004$ & $\begin{array}{c}\text { 760Aab } \\
(22)\end{array}$ & $\begin{array}{c}670 \mathrm{Ab} \\
(22)\end{array}$ & $\begin{array}{c}810 \mathrm{Aa} \\
(22)\end{array}$ & $\begin{array}{c}340 \mathrm{Aa} \\
(32)\end{array}$ & $\begin{array}{c}310 \mathrm{Aa} \\
(32)\end{array}$ & $\begin{array}{c}\text { 390Aa } \\
(32)\end{array}$ \\
\hline Média & $\begin{array}{c}740 \\
(7,2) \\
\end{array}$ & $\begin{array}{c}675 \\
(6,9) \\
\end{array}$ & $\begin{array}{c}770 \\
(7,2)\end{array}$ & $\begin{array}{l}315 \\
(33) \\
\end{array}$ & $\begin{array}{l}285 \\
(33) \\
\end{array}$ & $\begin{array}{l}385 \\
(33)\end{array}$ \\
\hline
\end{tabular}

${ }^{(1)}$ Médias seguidas de letras iguais, maiúsculas nas colunas e minúsculas nas linhas, não diferem entre si pelo teste de Tukey, a 5\% de probabilidade; os valores entre parênteses são os errros-padrão da média. 
período seco, para as cvs. Marandu, Piatã e Xaraés, respectivamente (Euclides et al., 2008b). As médias para a RFM foram de 1,5, 2,1 e 2,4, durante o período das águas, e de 0,5, 0,7 e 0,4, no período seco, para as cvs. Marandu, Piatã e Xaraés, respectivamente (Euclides et al., 2008b). Essas relações, provavelmente, determinaram as variações na produção animal, ao longo do ano, e podem ser confirmadas pelas correlações positivas entre o GMD e a relação lâmina foliar:colmo $(\mathrm{p}<0,01 ; \mathrm{r}=0,76)$, durante o período das águas, e relação lâmina foliar:material morto $(\mathrm{p}<0,01$; $r=0,67)$, durante o período seco. Esses dados indicam, assim, que a facilidade de seleção e preensão da lâmina foliar, pelos animais, foi influenciada principalmente pelo colmo, durante o período das águas; e pelo material morto, durante o período seco, o que resultou em menor ingestão de forragem pelo animal e, consequentemente, menor GMD.

Foram observados efeitos de cultivar $(\mathrm{p}<0,01)$, de período do ano $(\mathrm{p}=0,01)$ e da interação entre estes dois efeitos $(p<0,01)$ em relação à taxa de lotação (TL). Durante o período das águas, o pasto da cv. Xaraés suportou maior TL do que os pastos das outras cultivares; no período seco, não houve diferenças quanto à TL entre as cultivares (Tabela 7). A maior TL, registrada para a cv. Xaraés durante o período das águas, foi consequência do manejo adotado, uma vez, que ela foi ajustada de acordo com a disponibilidade de lâminas foliares (DLF igual à somatória da massa de LF, no pré-pastejo, com a estimativa de acúmulo de MSLF durante o período de ocupação); a TL foi, em média, $2.540,2.220$ e $2.030 \mathrm{~kg} \mathrm{ha}^{-1}$, respectivamente, para as cvs. Xaraés, Piatã e Marandu. Isto pode ser confirmado pela baixa correlação entre a massa de forragem no

Tabela 7. Médias dos quadrados mínimos, para a taxa de lotação (UA ha ${ }^{-1}$ ) dos pastos de $B$. brizantha cultivares Marandu, Xaraés e Piatã, de acordo com o período do ano $^{(1)}$.

\begin{tabular}{lccc}
\hline Cultivar & Período das águas & Período seco & Média \\
\hline Marandu & $2,7 \mathrm{Ba}$ & $1,3 \mathrm{Ab}$ & 2,0 \\
& $(0,04)$ & $(0,05)$ & $(0,03)$ \\
Xaraés & $3,8 \mathrm{Aa}$ & $1,4 \mathrm{Ab}$ & 2,6 \\
& $(0,04)$ & $(0,05)$ & $(0,03)$ \\
Piatã & $2,9 \mathrm{Ba}$ & $1,2 \mathrm{Ab}$ & 2,1 \\
& $(0,04)$ & $(0,05)$ & $(0,03)$ \\
\hline Média & 3,1 & 1,3 & - \\
& $(0,06)$ & $(0,08)$ & \\
(1)Médias seguidas de letras iguais, maiúsculas nas colunas e minúsculas nas \\
\multicolumn{4}{l}{ linhas, não diferem entre si pelo teste de Tukey, a 5\% de probabilidade; os } \\
\multicolumn{2}{l}{ valores entre parênteses são os erros-padrão da média. }
\end{tabular}

pré-pastejo e a TL $(\mathrm{p}<0,01 ; \mathrm{r}=0,28)$; no entanto, houve alta correlação $(p<0,01 ; r=0,67)$ entre a TL e a DLF. Resultado semelhante foi observado por Pereira et al. (2005), em experimento sob o mesmo manejo no Sul da Bahia, em que a cv. Xaraés suportou maior TL comparada à cv. Marandu. A mesma explicação se aplica para a redução drástica da TL, durante o período seco, e para a semelhança na capacidade de suporte entre as cultivares (Tabela 7), uma vez que, durante esse período, o crescimento dos pastos foi muito pequeno e semelhante entre as cultivares (Euclides et al., 2008b).

Vale ressaltar que parte da explicação para a maior capacidade de suporte do pasto da cv. Xaraés, durante o período das águas, pode ser atribuída a uma superestimativa do acúmulo de MSLF durante o período de ocupação e, consequentemente, no ajuste inadequado da TL, pois a oferta de MSLF foi inferior para esta cultivar, como apresentado anteriormente. Assim, o menor GMD dos animais que pastejaram a cv. Xaraés (Tabela 6), poderia ser atribuído à maior TL desses pastos (Tabela 7), pois, à medida que a TL aumenta, a produção por animal decresce (Almeida et al., 2002; Cândido et al., 2005; Barbosa et al., 2006; Machado et al., 2008). No entanto, não houve $(\mathrm{p}>0,05)$ correlação entre estas duas variáveis para a cv. Xaraés, o que indica que o ajuste da taxa de lotação foi adequado, uma vez que quando existe boa disponibilidade de forragem, a TL tem pouco efeito sobre a produção individual.

Independentemente da cultivar, os pastos suportaram maior $(p<0,01)$ TL durante o primeiro ano experimental do que no terceiro ano, e o segundo ano foi semelhante aos outros dois. As TL médias foram de 2,5, 2,3 e 2,1 UA ha ${ }^{-1}$, respectivamente, para o primeiro, segundo e terceiro ano experimental, o que acompanhou, de certa forma, a taxa de acúmulo de lâminas foliares que, segundo Euclides et al. (2008b) foi de 30,1, 28,0 e 24,3 $\mathrm{kg} \mathrm{ha}^{-1}$ por dia de MS, para o primeiro, segundo e terceiro ano, respectivamente. Pereira et al. (2005) também observaram queda na TL do primeiro para segundo ano de pastejo, para as cultivares Marandu e Xaraés, sob o mesmo manejo no Sul da Bahia.

O menor GMD obtido pelos animais que pastejaram a cultivar Xaraés foi compensado pela maior TL, o que resultou em maior $(\mathrm{p}<0,05)$ produtividade, em comparação às das cultivares Marandu e Piatã. As médias foram de 870, 705 e $660 \mathrm{~kg} \mathrm{ha}^{-1}$ de PC por ano, para as cvs. Xaraés, Piatã e Marandu, respectivamente. 
Resultados semelhantes foram obtidos por Pereira et al. (2005) para as cvs. Marandu e Xaraés, sob o mesmo manejo no Sul da Bahia.

Houve, também, efeito do ano experimental $(\mathrm{p}<0,01)$. A maior produtividade foi obtida no primeiro ano, em comparação à dos outros dois anos; as médias e seu erro padrão foram de 850,650 e $635(22,0) \mathrm{kg} \mathrm{ha}^{-1}$ de PC por ano, respectivamente, o que está de acordo com a estimativa feita por Macedo (2006) de que a produção dos pastos e, consequentemente, a produtividade animal, são $30-40 \%$ superiores, no primeiro ano de exploração, em relação aos anos subsequentes, quando o potencial produtivo não é limitado por problemas de clima, solo ou manejo animal inadequado. Além disso, apesar da adubação fosfatada de manutenção, houve decréscimo, do primeiro para o terceiro ano de utilização, nos teores de $\mathrm{P}$ no solo na camada de 0-20 $\mathrm{cm}$ de profundidade (Euclides et al., 2008b). O P desempenha papel prioritário na garantia de produção de forragem, e, consequentemente, na capacidade de suporte e na produtividade animal.

\section{Conclusões}

1. As relações lâmina foliar:colmo e lâmina foliar:material morto dos pastos das cultivares Marandu, Piatã e Xaraés são mais importantes do que o valor nutritivo das forragens, no controle do ganho de peso dos animais.

2. A produção por animal é maior em pastagem com a cultivar Piatã, e a produção animal por área é maior com a cultivar Xaraés.

\section{Agradecimentos}

À Fundação de Apoio ao Desenvolvimento do Ensino, Ciência e Tecnologia do Estado de Mato Grosso do Sul, pelo financiamento parcial do experimento; ao Conselho Nacional de Desenvolvimento Científico e Tecnológico e à Coordenação de Aperfeiçoamento de Pessoal de Nível Superior, pelas bolsas concedidas; ao Sr. Marcelo Paschoal de Oliveira, pela contribuição na condução do experimento.

\section{Referências}

ALMEIDA, R.G. de; NASCIMENTO JUNIOR, D.; EUCLIDES, V.P.B.; MACEDO, M.C.M.; REGAZZI, A.J.; BRÂNCIO, P.A.; FONSECA, D.M. da; OLIVEIRA, M.P. Produção animal em pastos consorciados sob três taxas de lotação, no Cerrado. Revista Brasileira de Zootecnia, v.31, p.852-857, 2002.

BARBOSA, M.A.A.; NASCIMENTO JUNIOR, D.; CECATO, U. Dinâmica da pastagem e desempenho de novilhos em pastagem de capim-tanzânia sob diferentes ofertas de forragem. Revista Brasileira de Zootecnia, v.35, p.1594-1600, 2006.

BRASIL. Ministério da Agricultura, Pecuária e Abastecimento. Requisitos mínimos para determinação do valor de cultivo e uso de braquiária (Brachiaria brizantha (Hochst. ex A. Rich.) Stapf, Brachiaria decumbens Stapf, Brachiaria ruziziensis R. Germ. \& C.M. Evrard), híbridos e populações resultantes de cruzamentos interespecíficos. 2008. Disponível em: $<$ http:// extranet.agricultura.gov.br/sislegis-consulta/consultarLegislacao. do;jsessionid $=\mathrm{c} 0 \mathrm{a} 802 \mathrm{c} 930 \mathrm{~d} 6480 \mathrm{~b} 917 \mathrm{add} 714 \mathrm{e} 568 \mathrm{~d} 28 \mathrm{eaa} 8 \mathrm{~b} 66 \mathrm{cc}$ 7ca.e3uQbh0LahaSe34SahyQahqSbNz0?operacao=visualizar\&i $\mathrm{d}=18970>$. Acesso em: 4 ago. 2008.

CÂNDIDO, M.J.D.; ALEXANDRINO, E.; GOMIDE, C.A.M.; GOMIDE, J.A.; PEREIRA, W.E. Período de descanso, valor nutritivo e desempenho animal em pastagens de Panicum maximum cv. Mombaça sob lotação intermitente. Revista Brasileira de Zootecnia, v.34, p.1459-1467, 2005.

DIAS-FILHO, M.B.;ANDRADE, C.M.S. Pastagens no ecossistema trópico úmido. In: REUNIÃO ANUAL DA SOCIEDADE BRASILEIRA DE ZOOTECNIA, 42., 2005, Goiânia. Anais. Goiânia: SBZ, 2005. p.94-104.

EMBRAPA. Sistema brasileiro de classificação dos solos. Brasília: Embrapa-SPI; Rio de Janeiro: Embrapa-CNPS, 1999. $412 \mathrm{p}$.

EUCLIDES, V.P.B.; CARDOSO, E.G.; MACEDO, M.C.M.; OLIVEIRA, M.P. de. Consumo voluntário de Brachiaria decumbens cv. Basilisk e Brachiaria brizantha cv. Marandu sob pastejo. Revista Brasileira de Zootecnia, v.29, p.2200-2208, 2000 .

EUCLIDES, V.P.B.; EUCLIDES FILHO, K. Uso de animais na avaliação de forrageiras. Campo Grande: Embrapa-CNPGC. 1998, 59p. (Embrapa-CNPGC. Documentos, 74). Disponível em: $<$ http:// www.cnpgc.embrapa.br/publicacoes/doc/doc_pdf/DOC074. pdf>. Acesso em: 10 dez. 2008.

EUCLIDES, V.P.B.; MACEDO, M.C.M.; DA SILVA, S.C.; NASCIMENTO JUNIOR, D.; VALLE, C.B. do; BARBOSA, R.A. Gramíneas cultivadas. In: ALBUQUERQUE, A.C.S.; SILVA, A.G. da. Desenvolvimento da agricultura tropical: quatro décadas de inovações tecnológicas, institucionais e políticas. Brasília: Embrapa Informação Tecnológica, 2008a. v.1. p.1071-1110.

EUCLIDES, V.P.B.; MACEDO, M.C.M.; OLIVEIRA, M.P. de. Avaliação de diferentes métodos de amostragem para se estimar o valor nutritivo de forragens sob pastejo. Revista Brasileira de Zootecnia, v.21, p.691-702, 1992.

EUCLIDES, V.P.B.; MACEDO, M.C.M.; VALLE, C.B. do; BARBOSA, R.A.; GONÇALVES, W.V.; OLIVEIRA, M.P. de. Produção de forragem e características estruturais de três cultivares de Brachiaria brizantha sob pastejo. Pesquisa Agropecuária Brasileira, v.43, p.1805-1812, 2008b

EUCLIDES, V.P.B.; VALLE, C.B. do; MACEDO M.C.M.; OLIVEIRA.M.P. de. Evaluation of Brachiaria brizantha ecotypes 
under grazing in small plot. In: INTERNATIONAL GRASSLAND CONGRESS, 19, 2001, Piracicaba. Proceedings. Piracicaba: Fealq, 2001. p.535-536.

MACEDO, M.C.M. Aspectos edáficos relacionados com a produção de Brachiaria brizantha cultivar Marandu. In: BARBOSA, R.A. Morte de pastos de braquiárias. Campo Grande: Embrapa Gado de Corte, 2006. p.35-65.

MACHADO, L.A.Z.; FABRÍCIO, A.C.; GOMES, A.; ASSIS, P.G.G. de; LEMPP, B.; MARASCHIN, G.E. Desempenho de animais alimentados com lâminas foliares, em pastagem de capimmarandu. Pesquisa Agropecuária Brasileira, v.43, p.1609-1616, 2008.

MARTEN, G.C.; SHENK, J.S.; BARTON II, F.E. Near infrared reflectance spectroscopy (NIRS): analysis of forage quality. Washington: USDA, 1985. 110p. (Agriculture Handbook, 643).

MORAES, E.H.B.K. de; PAULINO, M.F.; ZERVOUDAKIS, J.T.; VALADARES FILHO, S. de C; MORAES, K.A.K. de. Avaliação qualitativa da pastagem diferida de Brachiaria decumbens Stapf., sob pastejo, no período da seca, por intermédio de três métodos de amostragem. Revista Brasileira de Zootecnia, v.34, p.30-35, 2005.

NAVE, R.L.G. Produtividade, valor nutritivo e características físicas da forragem do capim-xaraés [Brachiaria brizantha (Hochst ex A. Rich.) Stapf] em resposta a estratégias de pastejo sob lotação intermitente. 2007. 94p. Dissertação (Mestrado) - Universidade São Paulo, Piracicaba. Disponível em: $\quad<$ http://www.teses.usp.br/teses/disponiveis/11/11139/ tde-21122007-092102/>. Acesso em: 28 jul. 2008.

PALHANO, A.L.; CARVALHO, P.C.F.; DITTRICH, J.R.; MORAES, A. de; DA SILVA, S.C.; MONTEIRO, A.L.G. Características do processo de ingestão de forragem por novilhas holandesas em pastos de capim-mombaça. Revista Brasileira de Zootecnia, v.36, p.1014-1021, 2007.

PEREIRA, J.M.; REZENDE, C. de P.; RUIZ, M.A.M. Pastagem no ecossistema Mata Atlântica: atualidade e perspectiva. In: REUNIÃO ANUAL DA SOCIEDADE BRASILEIRA DE ZOOTECNIA, 42, 2005, Goiânia. Anais. Goiânia: SBZ, 2005. p.36-55.

POPPI, D.P.; HUGHES, T.P.; L'HUILLIER, P.J. Intake of pasture by grazing ruminants. In: NICOL, A.M. (Ed.). Livestock feeding on pasture. Hamilton: New Zealand Society of Animal Production, 1987. p.55-64. (Occasional Publication, 10).

POSTIGLIONI, S.R. Potencial para produção de carne da Brachiaria brizantha cv. Marandu, Setaria anceps cv. Kazungula e Cynodon nlemfuensis cv. Coastcross-1 na região do Campos Gerais do Paraná, Brasil. Pastures Tropicales, v.20, p.9-14, 1998.

SAS INSTITUTE. SAS/STAT user's guide: statistics. Version 6. 4.ed. Cary: SAS Institute, 1996. v.1/2.

TRINDADE, J.K.; DA SILVA, S.C.; SOUZA JUNIOR, S.J. de; GIACOMINI, A.A.; ZEFERINO, C.V.; GUARDA, V.D.A.; CARVALHO, P.C.F. Composição morfológica da forragem consumida por bovinos de corte durante o rebaixamento do capimmarandu submetido a estratégias de pastejo rotacionado. Pesquisa Agropecuária Brasileira, v.42, p.883-890, 2007.

VALETIM, J.F.; AMARAL, E.F.; MELO, A.W.F. Zoneamento de risco edáfico atual e potencial da morte de pastagens de Brachiaria brizantha no Acre. Rio Branco: Acre, 2000. 28p. (Embrapa Acre. Boletim de pesquisa, 29). Disponível em: < http:// www.cpafac.embrapa.br./publicações $>$. Acesso em: $10 \mathrm{dez}$. 2008.

VALLE, C.B. do; EUCLIDES, V.P.B.; PEREIRA, J.M.; VALÉRIO, J.R.; PAGLIARINI, M.S.; MACEDO, M.C.M.; LEITE, G.G.; LOURENÇO, A.J.; FERNANDES, C.D.; DIAS-FILHO, M.B.; LEMPP, B.; POTT, A.; SOUZA, M.A. de. O capim-xaraés (Brachiaria brizantha cv. Xaraés) na diversificação das pastagens de braquiárias. Campo Grande: Embrapa Gado de Corte, 2004. 36p (Embrapa Gado de Corte. Documentos, 149). Disponível em: <http://www.cnpgc.embrapa.br/publicacoes/ doc/doc_pdf/Doc149.pdf>. Acesso em: 10 dez. 2008.

VALLE, L.C.S.; VALERIO, J.R.; SOUZA, O.C. de; FERNANDES, C.D.; CORREA, E.S. Diagnóstico de morte de pastagens nas regiões Leste e Nordeste do Estado do Mato Grosso. Campo Grande: Embrapa Gado de Corte, 2000. 13p (Embrapa Gado de Corte. Documentos, 97). Disponível em: <http://www.cnpgc. embrapa.br/publicacoes/doc/doc_pdf/DOC097.pdf $>$. Acesso em: 10 dez. 2008.

WALKER, J.W. Viewpoint: grazing management and research now and in the next millenium. Journal of Range of Management, v.48, p.350-357, 1995.

Recebido em 4 de setembro de 2008 e aprovado em 16 de dezembro de 2008 